Applied Mobilities - Extended book review

\title{
The gendered mobilities of sex work
}

Lesley Murray, School of Applied Social Science, University of Brighton. L.Murray@brighton.ac.uk

Day, S. and Ward, H. 2004. Sex work, mobility and health in Europe. London: Routledge 978-1138996076 £30.00 (paperback edition 2016)

Maher, J., Pickering, S and Gerard, A. 2013. Sex work: labour, mobility and sexual services. London: Routledge 978-0415630665 £34.99 (paperback)

\section{Introduction}

The association between female sexuality and mobility is centuries, even millennia, old, and features strongly in debates around the gendering of urban space (Parsons 2000; Massey 1994; McDonnell 1999). As recently as the nineteenth century the physical restricting of women in the domesticated space of the home was debated in UK parliament (Parkins 2009). Gendered mobilities including the relevance of the public/private dichotomy have been much debated more recently (Sheller and Urry 2003, Uteng and Cresswell 2008), but less so in relation to gendered mobile labour with the exception of scholarship on transnational migration (Benhabi and Resnick 2009; Walsh et. al 2013). Walsh et al. (2013: 262) argue that 'mobility, gender, and work intertwine in ways that reach to the core of gendered practices in everyday life, often reproducing traditional gendered relations but also creating spaces for new ones'. Mobile work, like other aspects of the social world, is uneven. This is particularly manifest in the sector of sex work, which is the subject of two books set, primarily, on opposite sides of the globe. Day and Ward's (first published in 2004 with a paperback version published in 2016) edited collection, Sex work, mobility and health in Europe, is based on an overview and case studies of sex work in the European context, whilst Maher, Pickering and Gerard's (2013) book on the intersections of sex work and mobility is based on case studies located in Australia.

\section{Mobilities at the centre of key debates}

Existing studies of sex work and mobility tend to conflate sex work with slavery and trafficking (see for example Jarvis et al. 2009) with broader discussions of mobilities focused on global trends in labour markets such as growth of sex tourism in Southeast Asia, and less on local contexts such as the ways in which this mobile work shapes the city and reinforces gendered spatialities. There is much debate in this field. Interestingly Jarvis et al. cite Bindel and Atkins (2007), who produced a report: Big Brothel in 2008 about the sex industry in London that was later the subject of a critical response endorsed by a number of academics (Sanders et. al. 2008) working in this field, including Sophie Day and Helen Ward. Bindel and Atkins $(2007,5)$ critique the term 'sex worker' as a term that 'dignifies and destigmatises the sex industry and the buyers/exploiters, and not the women in it' and undermines efforts to locate prostitution as a form of sexual violence'. Both Day and Ward and Maher et al. are concerned with contesting binarised accounts of sex work through research that focuses on the experiences of sex workers. More pertinently here, they both place mobility at the centre of their analysis and thereby present opportunities to develop ways in which a mobilities focused approach to sex work can produce insights into wider mobility concerns, particularly in relation to unevenness and inequality. For Day and Ward, 
mobility is one of four key themes of their edited collection - the being activism, policy development and health. Similarly, Maher et al.'s $(2013,1)$ main focus is on the mobility of sex workers: 'particularly across the borders of legal and illegal sex work, between regulated spaces an unregulated spaces, across national borders, and in and out of the sex industry.'

\section{Resisting binary accounts}

Both books critique the main debate in sex work, around 'toleration' and 'abolition', both arguing that scholarship has tended to become caught up in either one or the other to the detriment of a more comprehensive analysis. The first approach, premised on the problematic commodification of sex, they argue, does not take account of global market trends. The second approach, based on the viewing of sex work as violence against women is considered closely aligned to the anti-trafficking campaigns. Maher et al. $(2013,129)$ argue that 'moral crusade of anti-trafficking activities will inevitably restrict the remaining legitimate channels for women to migrate'. Day and Ward $(2004,3)$ suggest that the 'alarm' over trafficking has led to new and often contradictory policies to control sex work that have disadvantage poorer migrants from outside the EU as they aim to curb this influx. In this way, Day and Ward argue, exploitation and violence are actually increased as workers do not have any means of state support. They contest that this debate, between toleration and abolition, has marginalised sex workers as it detracts from the campaigns for unionisation and anti-discrimination laws. Instead a broader critique would encompass the range of inequalities produced in $21^{\text {st }}$ century market driven economies, which protect employers rather than workers. Both books argue that sex work cannot be separated from the social conditions that produce and sustain this industry, the 'gendered relations of household dynamics and identity formation', which Walsh et al. $(2013,262)$ identify in relation to the wider labour market. As Day and Ward $(2004,14)$ argue, sex work both 'subverts the family and props it up'.

\section{Sex work as work}

Three key themes emerge from these books, which are of particular significance for mobilities. Firstly, is the key argument, in both Day and Ward and Maher et al. that sex work is indeed work and therefore mobile work. Of course this links back to the key debates on sex work and the critique that such intimate work cannot be commodified. Day and Ward $(2004,14)$ argue that only through understanding sex work as work can we challenge the ways in which "prostitution is rooted in both the social and the economic organisation of society, and defined in the negative...'. Similarly, Maher et al. $(2013,11)$ argue that such a premise is necessary in order to fully understand the sexual services industry including its scope both within national borders and across borders globally...'. Both books argue that it is only when defined as work that the working conditions of sex work can be questioned and that this is only possible when research incorporates the voices of sex workers. Maher et al. argue that some feminists have used methods that have silenced sex workers, replacing their stories with versions based on their anti-sex work argument. They suggest instead that the materiality of body needs to be brought to the fore, as sex work is based on bodies interacting. Many studies, they argue, often do not take account of the body as a working body - so for example there is a lack of attention to safe work practices. Hence they advocate 'embodied epistemologies' (Ibid.,7) taking account of the ways in which women challenge the conditions of the global labour market, for example, sex workers' accounts of how they used their bodies mobility to control their interactions with clients in order to manage intimacy e.g. through maintaining boundaries of intimacy. They are careful not to undermine alternative research. Indeed, studies such as Smith and Hall's (2013) on outreach workers on the Streetlife project that seeks to influence the lives of those associated with sex work in Cardiff, produces insights on particular aspect of sex work, albeit 
from the outreach workers' perspective. Maher et al. $(2013,14)$ contend that, registered sex work needs to be seen as one element of sex work in 'a diverse and complex sexual services industry'.

\section{The global and the local}

A second common theme across both books is that sex work is both local and global; that the local and the global intersect in mobile sex work in a way that illuminates wider social relations, and in particular intimate relations. Maher et al. (2013) discuss the ways in which sex work results from inequalities in global pay and conditions especially for women in developing countries. Under these conditions transnational migration for sex work becomes a feasible option in offering financial security. Hence they suggest the need to consider ways in which global labour markets have changed in comparing this labour to other sectors of the service industry that require similar intimate exchanges between workers and clients. At the same time, in being 'bound to the local', they found that 'different work conditions and contexts produced different types of sex work labour' (lbid., 8). At the scale of the local, national regulatory conditions determine sex worker experiences, whilst at a regional scale in-migration to Europe is limited as a result of pan-European policy. Day and Ward describe the restrictions on movement within some countries in Europe - for example the banning of street prostitution in Finland. Maher et al. similarly illustrate differing local regulation such as UK regulations to try to reduce impact of sex work on communities. In a number of countries in the EU regulations on working conditions in brothels are not applicable to migrants. Then at the very local scale of the body, sex work becomes a site of agency, a site in which women can take control of their bodies as 'tools of their trade' (Maher et al. 2013). The body is seen to define women - as something sacred - but this is not universal identity forming as 'no single experience of the body is shared by everyone' (Agustín 2004, 89 in Day and Ward). Rather than a unique site of labour supply, however, Maher et al. (2013) argue that this level of intimacy can be compared to wider aspects of intimate care that women are expected to provide both within and outside the labour market. They contend that ideas around sexuality being the core of identity pervade in Western society so that sexual labour undermines selfhood more than other intimate forms of labour and is more problematically commercialized. Maher et al. argue that all intimate exchanges are determined through markets and commodification citing sociological studies of intimacy that question the disengagement of these relations from the market. The local site of the mobile body is therefore key in illustrating aspects of sex work that are hidden. Importantly too, Maher et al. discuss the changing world of communication technologies that 'dis-embody' and argue that sex work needs to be redefined in this context.

\section{Mobilities and sex work}

The third theme of importance here is that both books strongly indicate the insights that can be gained, for mobilities and for sex work scholarship, when looking at the intersections of mobility and mobile sex work. Gendered mobilities have been the focus of a number of recent studies of mobility and migration (Walsh et al. 2013; Yeoh and Ramdas 2014) but there is less emphasis on the potential insights from mobile work and mobile sex work in particular. For example, Walsh et al.'s $(2013,262)$ study of trends in the movement of international migrants might be enhanced by looking at the mobilities of sex workers as illustrative of the 'gendered practices within the context of work over the lifecourse'.

Cresswell (2010) talks of a politics of mobility in which engagements with mobility can inform broader social relations. In this context a spotlight on mobilities can help understand the ways in which, despite the mantra of free movement and increased mobilities, for many this results in restrictions on movement and immobility as these books illustrate. A focus on sex work also illuminates aspects of gendered mobilities that may not otherwise be vis ible. Day 
and Ward discuss the ways in which women who migrate are seen differently to men - as victims of trafficking - when women should be seen to be as resourceful as men in facing challenges of contemporary Europe. As Agustín (2004, 87), argues women are seen as 'essential or characteristic part of the home so denied agency to undertake a migration' In both books, sex workers are a highly mobile group with unique characteristics. Their migration is not only economic but, like first world migrants, is cultural. As Day and Ward illustrate, they are people who want to see new places and meet new people. They move from country to country, from city to city and are also highly mobile within the sex industry, moving between sectors. This means that they often do not establish roots nor assimilate into local cultures; they are prevented from becoming 'good'. Agustín $(2004,88)$ likens this to the position of nomadic groups like Roma with mobility 'seen as a social problem inside the west'.

\section{Conclusion}

Sex worker mobility and migration, as set out in both books, shows some of the stark consequences of the contemporary mobile world. However, as both books argue, in order to contribute to wider debates, there needs to be more nuanced accounts of this sector. With such accounts, such as those provided in these books, it is possible, for example to contribute to studies of intimate mobilities (see for example Holdsworth 2013) as 'sex work offers a unique intersection of physical intimacy, service work and global labour' (Maher et al. 2013,3 ) research on sex work as a practice that intersects with broader conditions of mobile labour. They argue that, set within dichotomy of powerful/powerless, means that aspects of sex work that reveal these changes are overlooked. Both of these books on sex work make a significant contribution to the understanding of mobile work and its gendering in particular. Such accounts, based on ethnographic studies of mobile experiences, but set within global contexts have much to offer to the field of mobilities.

\section{References}

Agustín, L. M. 2004. Daring border-crossers: a different vision of migrant women. In Day, S. and Ward, H. Sex work, mobility and health in Europe. London: Routledge.

Benhabib, S. and Resnik, J. 2009. Migrations and Mobilities: Citizenship, Borders and Gender. New York: New York University Press.

Bindel, J. and Atkins, H. 2007 Streets apart: outdoor prostitution in London. London: Poppy project/Eaves Housing for women.

Bindel, J. and Atkins, H. 2008. Big brothel: a survey of the off-street sex industry in London. Poppy Project/Eaves Housing for Women.

Cresswell, T. 2010. Towards a politics of mobility. Environment and Planning D: Society and Space 28,17-31.

Day, S. 2007. On the game: women and sex work. London: Pluto Press.

Holdsworth, C., 2013. Family and intimate mobilities. London: Palgrave Macmillan.

Jarvis, H., Kantor, P. and Cloke, J. 2009. Cities and Gender. London: Routledge.

Massey, D. 1994. Space, place and gender. Bristol: Polity Press.

McDowell, L. 2003. Space, place and home. In, Eagleton, M. (ed.) Feminist Theory. Blackwell: Oxford. 
Parkins, W. 2009. Mobility and modernity in women's novels: 1850s - 1930s: women moving dangerously. Basingstoke: Palgrave Macmillan.

Parsons, D. I. 2000. Streetwalking the metropolis: women, the city and modernity. Oxford: Oxford University Press.

Smith, R. J. and Hall, T. 2013. No time out: mobility, rhythmicity and urban patrol in the twenty-four hour city The Sociological Review61(S1): 89-108.

Uteng, T.P and Cresswell, T. 2008. Gendered mobilities. London: Routledge.

Walsh, D. Valestrand, H. Gerrard, S. and Aure, M. 2013. Gendered Mobilities in the North: Advancing an International Comparative Perspective. Norsk Geografisk Tidsskrift Norwegian Journal of Geography 67(5): 260-265.

Yeoh, B. \& Ramdas, K. 2014. Gender, migration, mobility and transnationalism, Gender, Place \& Culture, 21(10): 1197-1213.

Sanders, T., Pitcher, J., Campbell, R., Brooks-Gordon, B. and O'Neil, M., 2008. An Academic Response to "Big Brothel". Accessed via uknswp. org. Accessed 21 July 2016 at http://www.uknswp.org/wp-content/uploads/AcademicResponseBigBrothelFinSept2008.pdf

Sheller, M. and J. Urry. 2003. "Mobile transformations of 'public' and 'private' life." Theory, culture and society 20: 107-125. 